\title{
As políticas públicas acessadas pelos agricultores familiares associados à COOESPERANÇA: PRONAF E PNAE
}

\author{
Rita Inês Paetzhold Pauli ${ }^{\mathrm{I}}$ Ednalva Felix das Neves ${ }^{\mathrm{II}}$
}

\begin{abstract}
Resumo:
Este artigo tem por objetivo descrever e analisar as políticas públicas direcionadas aos empreendimentos de Economia Solidária, mais especificamente, busca-se mostrar como essas políticas públicas vêm se constituindo como elementos relevantes de desenvolvimento sócio territorial dos empreendimentos da Cooperativa Mista dos Pequenos Produtores Rurais e Urbanos vinculados ao Projeto Esperança (COOESPERANÇA). Os procedimentos partem de uma revisão bibliográfica e perpassam por uma rápida análise de alguns dados secundários da SENAES e de resultados da aplicação direta de questionários aos agricultores familiares vinculados a COOESPERANÇA. A literatura especializada permitiu compreender que vem ocorrendo uma concentração de recursos no segmento mais capitalizado do que compõe o universo da agricultura familiar. Os resultados específicos mostram que uma parcela dos agricultores familiares vinculados à COOESPERANÇA acaba tendo participação mais restrita, e parte deles encontram-se alijados em termos de acesso a essa política pública. Ademais, verificou-se que apesar da importância do Programa Nacional da Agricultura Familiar (PRONAF) e do mercado institucional criado pelo Programa Nacional de Alimentação Escolar (PNAE) ainda persistem outros problemas, em ambos os casos, tal como dificuldades de operacionalização, e fragilidades na assistência técnica de extensão rural.
\end{abstract}

Palavras-chave: Políticas públicas; Agricultura familiar; PRONAF; PNAE

IProfessora associada e pesquisadora do Departamentode Economia e Relações Internacionais da Universidade Federal de Santa Maria - rita.pauli@gmail.com

IIPesquisadora do Pós-doutorado do Programa de Pós-graduação em Economia e Desenvolvimentos da Universdade Federal de Santa Maria-RS - ednalvafelix@gmail.com 


\section{Introdução}

As políticas públicas acessadas pela agricultura familiar têm sido abordadas nas últimas décadas, majoritariamente, a partir da análise de volume de recursos, grupos beneficiados e seus efeitos mais gerais sobre o segmento da agricultura familiar diversificada. Trata-se de estudos importantes, mas há lacunas na análise do significado de políticas públicas para o segmento da agricultura familiar vinculado à Economia Solidária (ES). A relevância desses estudos decorre do reconhecimento de que muitos Empreendimentos de Economia Solidária (EES) contam com tempo de existência reduzido, exatamente por sua fragilidade estar relacionada aos problemas de financiamento das atividades e de inserção mais efetiva no mercado.

Diante disso, acredita-se que a promoção de estudos tendo como palco de análise experiências consolidadas de (ES) identificando o acesso de seus cooperados a algumas políticas públicas, pode se apresentar como um bom caminho para compreender a importância de diferentes tipos de apoio público para garantir a longevidades dessas iniciativas. No Rio Grande do Sul, em um periodo recente, é importante destacar a experiência da Cooperativa Mista dos Pequenos Produtores Rurais e Urbanos vinculados ao Projeto Esperança (COOESPERANÇA) ${ }^{1}$, uma experiência que nasceu em 2003 com o objetivo de articular os empreendimentos associados ao projeto "para uma maior articulação dos produtores (as) e consumidores (as) para motivar o Comércio Justo, o Consumo Ético e Solidário através dos locais de Comercialização Direta dos Municípios da região Centro e a articulação dos Empreendimentos entre si” (ESPERANÇA/COOESPERANÇA, 2019, online). Também denominada de Teia Esperança, o projeto conta com mais de "mais de 40 espaços fixos de comercialização direta" nos municípios regionais que são sede dos produtores locais que participam do projeto e tem como sede (que é também ponto de articulação e integração) o Feiral Colonial, que fica situado na região central de Santa Maria. Neste espaço, são comercializados "produtos coloniais, hortigranjeiros ecológicos, caseiros, artesanais, panificação, confecção, serigrafia, artesanto em material reciclado, produtos da agroindústria familiar, carne (...) e prestação de serviços”, etc. (ESPERANÇA/COOESPERANÇA, 2019, online).

A partir da participação ativa dos associados da COOESPERANÇA e o protagonismo de suas lideranças de apoio vêm promovendo uma participação na formulação dos Planos municipais para o desenvolvimento de estratégias de inserção e manutenção de espaços de atuação em nivel nacional e internacional (Plano Estratégico de Desenvolvimento de Santa Maria (2013). A visão do eixo é "transformar o município de Santa Maria e a região em um centro de referência no fortalecimento de um modelo de organização e sustentabilidade da sociedade, baseado em valores e princípios de comércio justo e solidariedade. Tradicionalmente, há diferentes eventos nacionais e internacionais promovidos e sediados pela economia solidária de Santa Maria, como: Feira Estadual de Cooperativismo, Feira Econômica de Solidariedade do Mercosul, Fórum Social Mundial e Feira Municipal de Economia Solidária.

Os Objetivos Estratégicos do Eixo da Economia Solidária, cujas propostas estão incluídas no Plano Estratégico de Desenvolvimento de Santa Maria (2013) são: 1) articular a elaboração de políticas de Economia Solidária nos três níveis de governo; 2) qualificar a Feira Internacional de Economia Solidária (FEICOOP); 3) ter um espaço de comercialização no centro da cidade; 4) promover a disseminação da economia solidária nas escolas; 5) qualificar a grande feira colonial; 6) registrar a história e divulgar a proposta de economia solidária (Plano Estratégico de Desenvolvimento de Santa Maria, 2013, p. 62).

Cada um dos objetivos explicitados no Plano Estratégico de Desenvolvimento é composto de proposições específicas. Ressalta-se que o primeiro objetivo, é bastante amplo e insere as aspirações em relação a importância das políticas públicas, nas quais são delineadas as formas de viabilizar a aprovação da Lei Nacional e da Economia Solidária. Além disso, propõe-se a criação de um Fundo Municipal de Economia Solidária e o alinhamento das políticas locais às políticas estaduais e federais de Economia Solidária, bem como a manutenção da representação do município de Santa Maria, nas três esferas governamentais dos Conselhos de Economia Solidária. É proposta, também, a criação da Superintendência Municipal de Economia Solidária, em conjunto com a Secretaria Municipal de Desenvolvimento (Plano Estratégico de Desenvolvimento de Santa Maria (2013, p.65).

Por fim, desenvolvimento e a consolidação da COOESPERANÇA, ao longo dos seus 30 anos de existência, mostra que o município de Santa Maria -RS não apenas possui uma estratégia para moldar proativamente o local e as pessoas no local que justificariam o apoio pela sua permanência, mas também possui uma trajetória de ação e discussão em fóruns ampliados, tendo incorporado novos elementos criativos e reformulado de forma inovadora outras iniciativas de geração de trabalho e renda. Atingido esse grau de maturidade, torna-se evidente o potencial de transformação sistêmica que projetos dessa natureza podem causar na sociedade.

Este trabalho tem por objetivo tecer considerações acerca da importância das políticas públicas direcionadas aos empreendimentos de Economia Solidária, mais especificamente, busca-se mostrar como algumas políticas públicas vêm se constituindo como elementos relevantes de desenvolvimento sócio territorial dos empreendimentos da Cooperativa Mista dos Pequenos Produtores Rurais e Urbanos vinculados ao Projeto Esperança (COOESPERANÇA). Uma análise da capacidade de fomento das explorações agrícolas via Programa Nacional da Agricultura Familiar (PRONAF) e de inserção em mercados institucionais, como no caso do Programa Nacional de Alimentação Escolar (PNAE) é analisada a partir de outras temáticas transversais como: i) o contexto das intenções de busca de crédito

1 Disponível em: https://www.esperancacooesperanca.org/cooesperana. Acesso em 02/12/2019. 
para financimento dos empreendimentos de economia solidária no Rio Grande do Sul; ii) da intersetorialidade das políticas públicas de compras intitucionais (PNAE).

\section{As políticas públicas para o fortalecimento do trabalho e desenvolvimento da economia solidária}

A ideia de que o livre jogo das forças de mercado daria conta de solucionar os problemas sociais ficou ainda mais evidente após a segunda guerra mundial, respaldando, assim, o aumento da intervenção do Estado na sociedade (DI GIOVANNI, 2009). Nesta perspectiva, estas políticas teriam se mantido por várias décadas, culminando no período conhecido como os trinta anos gloriosos. No último quarto do século XX, no entanto, com a difusão dos ideais neoliberais, estas políticas foram colocadas em xeque.

A intervenção do Estado na sociedade civil é uma das maiores conquistas do século XX, possibilitando tanto a ampliação do campo de ação administrativa, como da técnica, isto é, os estudos sobre as políticas públicas (MÜLER, 2002, p. 19; 23). O autor define política pública como sendo "um programa de ação governamental em um setor da sociedade ou um espaço geográfico".

Não é possível escolher uma única (ou melhor) definição do que são políticas públicas, isto porque, conforme discorre Souza (2006), vários pensadores ofereceram contribuições para um amplo entendimento do tema. Contudo, é possível resumir suas contribuições, de maneira a se chegar a um entendimento dos elementos teóricos constitutivos de uma abrangente base conceitual. Neste sentido, a autora resume política pública como "o campo do conhecimento que busca, ao mesmo tempo, 'colocar o governo em ação' e/ou analisar essa ação (variável independente) e, quando necessário, propor mudanças no rumo ou curso dessas ações (variável dependente)" (SOUZA, 2006, p. 07).

Ainda no que se refere ao entendimento sobre o tema, Deubel (2006) considera que as políticas públicas vão além da resolução de problemas. Em uma conotação mais ampla, o autor mostra que as políticas públicas contribuem tanto para a construção de um marco de redefinição dos problemas, como para a busca de soluções para eles, pelos atores sociais. Sob esta perspectiva, as políticas públicas atuam na construção de uma nova representação dos problemas, e a participação dos atores favorece o estabelecimento de condições sócio-políticas para resolução.

A entrada (ou não) na agenda política ou pública apenas aponta para a lista de problemas que o governo em questão prioriza (ou não). Cabe, portanto, aos grupos sociais a construção e organização de suas prioridades, bem como a formulação de estratégias capazes de pressionar "espaços" de influência sobre a agenda pública. Neste sentido, vale evidenciar que a formulação das políticas representa o estágio em que os governos democráticos concretizam suas plataformas eleitorais em programas e ações que perpassam o mundo das ideias, resultando no mundo real (SOUZA, 2006).

Uma conjuntura econômica permeada por desemprego, precarização, exclusão, desigualdade, descenso da luta social e política neoliberal traduz a manifestação de um movimento de expansão da econômia solidária, das experiências econômicas concretas, de empreendimentos econômicos solidários, e da crescente opção dos movimentos sociais, sindical, universidades e organizações populares por uma nova forma de luta social a partir da organização econômica das pessoas (SCHIOCHET, 2009).

Schiochet mostra que muitos EES surgiram a partir do desenvolvimento de algumas políticas públicas, por exemplo, no âmbito do Programa de Desenvolvimento Local e Integrado e Sustentável (Dlis) e do Plano Nacional de Qualificação Profissional (Planfor). Os dados do Sistema Nacional de Informações em Economia Solidária (Sies) também demonstram a importância do apoio governamental (vários órgãos e instâncias) para o surgimento da ES no país ao longo da década de 1990 (SCHIOCHET, 2009).

Na década de 2000, o Programa de Economia Solidária em Desenvolvimento, incentivado e elaborado pelo Governo Federal, através da SENAES visava promover a articulação de políticas públicas de geração de trabalho e renda ao combate a pobreza e à inclusão social e foi aproveitada toda uma estruturação de redes já existente, tais como as prefeituras municipais e governos estaduais. O programa buscava, através da Rede Nacional de Gestores Públicos de Políticas de Fomento à Economia Solidária, construir a integração de políticas com vistas a sua consolidação.

No Brasil, juntamente com a extinção do Ministério do Trabalho e Emprego (MTE), também foi extinta a Secretaria Nacional da Economia Solidária (SENAES) que teve suas atribuições relegadas ao Ministério da Cidadania. Vale lembrar que, na atual configuração não há espaço para definir estratégias de desenvolvimento, tal como havia na estruturação anterior, isto é não estimulando o cooperativismo e associativismo e demais políticas transversais. O quadro atual das políticas específicas para a Economia Solidária está sendo reduzida a uma política meramente assistencial, tanto em relação aos objetivos quanto ao reduzido volume de recursos financeiros a ela direcionada. 


\section{As políticas públicas da agricultura familiar acessadas pelos associados da COOESPERNÇA}

No que se referem às especificidades dos atores sociais do meio rural, sabe-se que nem todos se dedicam à atividade agrícola, uma vez que este meio também passou a desenvolver, nas últimas décadas o trabalho em tempo parcial e a pluriatividade. Apesar disso, destaca-se ainda neste território o desenvolvimento da parte agrícola da maior parcela dos cultivos temporários e permantentes da atividade agrícola. Em um contexto ampliado, e no caso brasileiro, parte significativa de Empreendimentos Econômicos Rurais (EER) são vinculados à Economia Solidária, e esses, tais como as demais explorações agrícolas pertencentes ao universo da agricultura familiar, vêm contando com oportunidades de fortalecimento especialmente a partir do Programa Nacional da Agricultura Familiar (PRONAF) e do Programa Nacional de Alimentação Escolar (PNAE). O Programa de Aquisição de Alimentos (PAA) já teve importância crucial para a aquisição de alimentos da agricultura familiar, porém essa política pública vem sendo desmontada gradativamente, e restringindo-se atualmente, um alcance limitado aos agricultores de médio porte. Por conseguinte, apresentando importância reduzida aos agricultores menos capitalizados.

Assim, as políticas públicas e os instrumentos para acesso da agricultura familiar para financiamento de Investimento e Custeio foram ampliados especialmente a partir de 1995, com a criação do PRONAF. No que concerne às políticas de inserção em mercados institucionais, o PNAE, especialmente a partir do final da década passada, vem ampliando as possibilidades de articulação da agricultura familiar aos mercados. Em 2009, foram regulamentadas as diretrizes de execução do PNAE, e - por meio da Lei no 11.947/2009 e da resolução no 38/FNDE/2009 - foi determinado que no mínimo $30 \%$ das aquisições de alimentos para as escolas públicas deveriam ser, preferencialmente, constituídas por alimentos orgânicos e adquiridos diretamente da agricultura familiar local ou regional.

Embora este trabalho não tenha a pretensão de realizar uma análise mais ampla dos estudos que enfatizam a importância dos sistemas alimentares localizados e a contraposição de modelos dominantes e alternativos (SONINO E MARSDEN 2006; GOODMAN 2004), ele pretende lembrar que a agricultura orgânica e agroecológica são, majoritariamente, escolhas produtivas dos agricultores familiares vinculados às cooperativas e associações de Economia Solidária. E isso se deve ao fato de que, na Economia Solidária verifica-se a conscientização pautada nos princípios de igualdade e, por isso promovem a responsabilidade coletiva através do diálogo, da gestão participativa e da preocupação com o todo. A produção e consumo de alimentos saudáveis se constituem em objetivos dessas organizações para atender a toda a sociedade, e ao mesmo tempo promover uma relação harmônica com a natureza.

Tendo em vista a importância das políticas públicas para a agricultura familiar, e considerando o destaque de alguns programas de desenvolvimento territorial para os agricultores familiares vinculados a COOESPERANÇA, as próximas subseções incursionam, de forma mais detida, em duas políticas públicas voltadas para as atividades agrícolas, a saber: i) de crédito (PRONAF) e; ii) de comercialização (PNAE). Este último vincula parte das compras institucionais de aquisição de alimentos para as escolas públicas do município de Santa Maria e de outros municipios pertencentes à região central do RS no território de abrangência da COOESPERANÇA.

\section{Limites e potencialidades dos PRONAF como fator estímulo ao financiamento dos empre- endimentos agrícolas da COOESPERANÇA}

De forma geral, as políticas para o desenvolvimento da agricultura brasileira tiveram um caráter geral até o final da década de 1970, através do Sistema Nacional de Crédito Rural (SNCR). Vale lembrar, que até meados da década de 1990, o país não contava com nenhum tipo de política pública específica para os agricultores familiares, com abrangência nacional. Em 1995, foi criado o Programa Nacional de Fortalecimento da Agricultura Familiar (PRONAF). Abramovay e Veiga mostram algumas especificidades das duas principais linhas do programa: o PRONAF-M crédito, destinado à infraestruturas e serviços, e como PRONAF-C crédito, destinado a custeio e investimento:

A existência de uma política de crédito voltada à agricultura familiar encontra sua justificativa naquilo que os economistas chamam de falha de mercado: a contribuição positiva desse setor à ocupação e geração de renda no campo é inibida por dois fatores básicos: pela ausência de condições infra estruturais para a valorização de seu trabalho, tema ao qual o PRONAF-M pretende responder, e pelas dificuldades que o setor bancário opõe a que um segmento dotado de precária base patrimonial e incapaz de oferecer contrapartidas faça parte de sua clientela regular (ABRAMOVAY e VEIGA 1999, p. 26).

O PRONAF-M tem o objetivo de promover investimentos baseados em compromissos negociados entre os beneficiários, os poderes municipais e estaduais, e a sociedade civil, possibilitando: a) a implantação, ampliação, modernização, racionalização e relocalização de infraestrutura necessária ao fortalecimento da agricultura familiar; e b) a ampliação e cobertura de serviços de apoio, a exemplo da pesquisa agropecuária e da assistência técnica e extensão rural. Para que se realize os investimentos em infraestrutura via recursos do PRONAF é preciso que o projeto atenda 
três orientações: (i) atuar de acordo com as demandas formuladas pelos agricultores familiares e/ou por suas organizações; (ii) descentralizar pessoal e processos de trabalho, aproximando-os o mais possível das realidades locais; e (iii) concentrar esforços na busca de respostas integrais para os sistemas de produção típicos da agricultura familiar (ABRAMOVAY e VEIGA, 1999).

De acordo com os referidos autores, o PRONAF C, que é destinado a crédito para custeios e investimentos, passou a admitir agricultores familiares que empregavam até dois assalariados permanentes, o que gerou duas consequências relevantes: a primeira é que se tornam candidatos ao crédito PRONAF agricultores com capacidade de oferecer aos bancos garantias reais e contrapartidas, e que tenderão a absorver parte significativa dos recursos, principalmente de investimento. A segunda é que aumenta a participação do sindicalismo patronal na execução local do PRONAF.

Os autores destacam a necessidade de haver o cuidado para que os recursos destinados ao PRONAF C não sejam concedidos aos agricultores patronais ou profissionais liberais que possuam áreas inferiores a quatro módulos rurais - uma das suas principais normas é que $80 \%$ da renda familiar deve vir da agropecuária, reduzindo, assim, as chances de os recursos serem desviados dos agricultores indo para os donos de terras que não produzem. Os autores enfatizam, ainda, que a maior parte dos recursos está destinada a estados e municípios onde a agricultura familiar possui maior força econômica, e que apresentam maior integração agroindustrial (ABRAMOVAY e VEIGA, 1999).

Se, por meio do PRONAF-C, for ampliada a quantidade de agricultores em condições de aumentar sua renda com base na integração agroindustrial, seus objetivos, quanto a essa linha, estão sendo cumpridos (ABRAMOVAY e VEIGA, 1999). As principais alterações no PRONAF ocorreram a partir de 1999, quando os agricultores beneficiários foram divididos em grupos distintos, com base principalmente na renda bruta anual, com a intenção de atender melhor à realidade de cada grupo.

Os agricultores familiares com menor faixa de renda e em maior dificuldade produtiva obtiveram maiores descontos e menores encargos financeiros. Surgiram também algumas linhas de crédito para atividades especiais, a exemplo da agroecologia, e para grupos específicos (mulheres, jovens e pescadores). Além disso, o Banco Central definiu taxa fixa e redução progressiva dos encargos financeiros por operação de crédito, bem como a ampliação de prazos e carências para os agricultores quitarem suas dívidas. Esse conjunto de mudanças institucionais possibilitou que maior número de agricultores familiares tivesse acesso ao programa, esses que, até então, estavam excluídos do sistema financeiro (SILVA, 2011).

O extinto Ministério do Desenvolvimento Agrário (MDA) que, desde 2016, foi rebaixado à condição de secretaria (Secretaria Especial de Agricultura Familiar e do Desenvolvimento Agrário da Casa Civil da Presidência da república - Sead), especifica diferentes linhas de créditos. O Quadro 1 mostra os subprogramas do Pronaf, a quem se destina e como solicitar apoio.

QUADRO 1. Subprogramas do PRONAF e linhas de financiamento

\begin{tabular}{|c|c|}
\hline$\underline{\text { Pronaf Agroindústria }}$ & $\begin{array}{l}\text { agricultores e produtores rurais familiares, pessoas físicas e jurídicas, e a cooperativas para } \\
\text { investimento em beneficiamento, armazenagem, processamento e comercialização agrícola, } \\
\text { extrativista, artesanal e de produtos florestais; e para apoio à exploração de turismo rural. }\end{array}$ \\
\hline$\underline{\text { Pronaf Mulher }}$ & $\begin{array}{l}\text { mulher agricultora integrante de unidade familiar de produção enquadrada no Pronaf, } \\
\text { independentemente do estado civil. }\end{array}$ \\
\hline$\underline{\text { Pronaf Agroecologia }}$ & $\begin{array}{l}\text { agricultores e produtores rurais familiares, pessoas físicas, para investimento em sistemas de produção } \\
\text { agroecológicos ou orgânicos, incluindo-se os custos relativos à implantação e manutenção do empreendimento. }\end{array}$ \\
\hline Pronaf ECO: & $\begin{array}{l}\text { agricultores e produtores rurais familiares, pessoas físicas, para investimento na utilização de } \\
\text { tecnologias de energia renovável, teçnologias ambientais, armazenamento hídrico, pequenos } \\
\text { aproveitamentos hidroenergéticos, silvicultura e adoção de práticas conseryacionistas e de correção } \\
\text { da acidez e fertilidade do solo, visando sua recuperação e melhoramento da capacidade produtiva. }\end{array}$ \\
\hline$\underline{\text { Pronaf Mais }}$ & $\begin{array}{l}\text { agricultores e produtores rurais familiares, pessoas físicas, para investimento em sua estrutura } \\
\text { de produção e serviços, visando ao aumento de produtividade e à elevação da renda da família. }\end{array}$ \\
\hline$\underline{\text { Pronaf Jovem }}$ & $\begin{array}{l}\text { agricultores e produtores rurais familiares, pessoas físicas, para investimento nas atividades de producão, } \\
\text { desde que beneficiários sejam maiores de } 16 \text { anos e menores de } 29 \text { anos entre outros requisitos. }\end{array}$ \\
\hline$\underline{\text { Pronaf Mais }}$ & $\begin{array}{l}\text { agricultores e produtores rurais familiares, pessoas físicass, para investimento em sua estrutura } \\
\text { de produção e serviços, visando ao aumento de produtividade e à elevação da renda da família. }\end{array}$ \\
\hline$\underline{\text { Pronaf Jovem }}$ & $\begin{array}{l}\text { agricultores e produtores rurais familiares, pessoas físicas, para investimento nas atividades de producão, } \\
\text { desde que beneficiários sejam maiores de } 16 \text { anos e menores de } 29 \text { anos entre outros requisitos. }\end{array}$ \\
\hline $\begin{array}{l}\text { Pronaf Microcrédito } \\
\text { (Grupo “B”) }\end{array}$ & $\begin{array}{l}\text { agricultores e produtores rurais familiares, pessoas físicas, que tenham obtido renda bruta familiar de até R\$20 } \\
\text { mil, nos } 12 \text { meses de produção normal que antecederam a solicitação da Declaração de Aptidão ao PRONAF(DAP). }\end{array}$ \\
\hline Pronaf Cotas-Partes: & $\begin{array}{l}\text { para integralização de cotas-partes por beneficiários do Pronaf associados a cooperativas } \\
\text { de produção rural; e e aplicação pela cooperativa em capital de giro, custeio, investimento ou } \\
\text { saneamento financeiro. }\end{array}$ \\
\hline
\end{tabular}


Vale ressaltar que nem todos os integrantes de municípios estão aptos a solicitar financiamento via PRONAF, apenas os municípios que possuem o Plano Municipal de Desenvolvimento Rural (PMDR) - documento oficial do município, que deve ajudar a obtenção de recursos necessários à implementação de ações orientadas para o fortalecimento da agricultura familiar, aprovado pelo Conselho Municipal de Desenvolvimento Rural (CMDR). (BRASIL, 2019, online).

Com relação ao Quadro 1, reitera-se que se trata de resultados históricos de mais de vinte anos de aprimoramento e inclusão de grupos sociais, anteriormente excluídos dessa política pública. Ademais, o PRONAF passou por mudanças institucionais e financeiras desde a sua implantação, de maneira que o volume de recursos aumentou progressivamente, facilitando o acesso de maior número de agricultores familiares ao crédito. A criação do PRONAF, resultou na necessidade de outras políticas diferenciadas para o desenvolvimento rural, assim como a criação do Ministério do Desenvolvimento Agrário (MDA) em 1999, e no âmbito deste a criação da Secretaria da Agricultura Familiar (SAF) em 2001 (SOUZA-ESQUERDO e BERGAMASCO, 2014; GRISA e SCHNEIDER, 2015).

De acordo com Aquino, Gazzola e Schneider (2017) está ocorrendo inovação institucional no financiamento público da produção agroecológica. Os autores referem-se ao Plano Nacional de Agricultura Orgânica (Planapo) que se insere no escopo das "linhas de crédito verde". O Planapo foi instituído no Brasil em 2013, com o objetivo de promover ações indutoras visando ampliar e fortalecer a produção orgânica de base agroecológica tendo como público prioritário os agricultores familiares e outros empreendimentos rurais vinculados à agricultura comercial.

\section{O mercado institucional do PNAE}

Os princípios de segurança alimentar e nutricional no mundo têm enfatizado as necessidades qualitativas de alimentos. No Brasil o programa público implementado pelo governo federal (o PNAE) vem incorporando seus princípios em suas próprias diretrizes e práticas. A referência aos centros de suprimento de alimentos no Brasil valoriza agricultura familiar, diversidade alimentar, produção local e preocupações sobre as formas de produção e consumo, segurança alimentar e nutricional tornam-se o novo elemento nos mercados apoiados e estruturados pelo Estado (FORNAZIER e BELIK, 2013; GRISA e PORTO, 2015).

A Constituição Federal de 1988 representou um marco legal para a agricultura familiar para além das possibilidades de acesso às políticas públicas de fomento da produção, conforme visto da subseção anterior, mas oportunizou à categoria social da agricultura familiar novos espaços para participação social, com a ampliação de políticas públicas capazes de permitir uma maior viabilização dos empreendimentos através das compras institucionais. A partir de 2003 foram construídas e institucionalizadas no Brasil políticas públicas para a agricultura familiar tendo como base a construção de mercados para a segurança alimentar e a sustentabilidade (GRISA e SCHNEIDER, 2015).

Os novos mercados criados nem sempre são "novos" no sentido da inexistência deste, para produtos específicos. Muitas vezes trata-se de uma mercantilização de valores-de-uso, isto é, produtos que antes eram produzidos em pequena escala para o próprio consumo que passaram a ser mercantilizados. As novas oportunidades incluem desde a inserção destes agricultores em mercados de nicho nacionais e internacionais, como se verifica nos produtos artesanais, com denominação de origem e nos orgânicos, até o aprimoramento dos circuitos regionais de produção, distribuição e consumo de alimentos (MALUF, 2004).

$\mathrm{O}$ aspecto territorial está presente na temática da agricultura familiar, principalmente sob três aspectos. Em primeiro lugar, as estratégias utilizadas para agregação de valor dos produtos agrícolas pelos próprios agricultores familiares, pautadas na construção de uma identidade territorial, de onde advém parte significativa do valor que se deseja atribuir aos bens. O segundo aspecto está relacionado ao território, pois permite introduzir a possibilidade de aproximar as relações entre a produção e o consumo dos alimentos, em que os fatores positivos se concentram na qualidade e confiabilidade dos produtos e na sua maior identificação por meio de hábitos de consumo diferenciados. O terceiro aspecto se refere aos projetos produtivos dos agricultores inseridos em uma dinâmica regional, a abordagem espacial-territorial aumenta as possibilidades de eventuais benefícios de aglomeração (MALUF, 2004).

Ainda de acordo com o referido autor, a elaboração de ações públicas voltadas à promoção da produção e do consumo de alimentos regionais de qualidade, sob forma de programas do governo e projetos que envolvam organizações não governamentais e entidades representativas dos agricultores e dos consumidores são prioritárias. Neste contexto vislumbra-se a importância dos sistemas de produção cooperativados, tal como são os EES, como formas de atuação democrática em que os benefícios econômicos e sociais podem ser amplificados.

A importância na criação de mercados institucionais para a agricultura familiar decorre de vários fatores: i) pela dificuldade de inserção nos mercados convencionais ii) os elevados custos de transportes; iii) dificuldades no "pleno conhecimento" de preços; iv) conhecimento de processos de comercialização; v) planejamento da produção, etc. O estabelecimento de uma demanda ex ante, e que garanta um mercado regular funciona como elemento importante na garantia de renda para os agricultores familiares e fortelece os sistemas cooperativados.

Nesse interím, é importante abordar a questão da intersetorialidade da política pública PNAE. A importância dos 
mercados institucionais reside na criação de mercados para além daqueles estabelecidos pelo livre jogo das forças de mercado, que com o desenvolvimento capitalista tornam-se concentrados reduzindo os "espaços" de produtores de menor capacidade de concorrencia. Os mercados institucionais são instrumentos de intervenção estatal que primam pela transversalidade e intersetorialidade na sua implementação, e foram incorporados gradativamente na agenda oficial do Estado brasileiro em busca do desenvolvimento rural. Os mercados institucionais que compram alimentos dos agricultores familiares para suprir demandas das escolas, e de instituições que atendem pessoas em situação de insegurança alimentar "visam atuar simultaneamente em questões como a inserção socioprodutiva, segurança e educação alimentar, geração de trabalho e renda, incentivo à agroecologia, etc.” (BECKER et al., 2014, p. 2).

Os programas que envolvem a alimentação escolar atenuam os efeitos provocados pela tendência globalizada na linha dos produtos processados, pois incorporam na dieta alimentar dos estudantes o consumo de produtos in natura. Além de incitarem a sistemas de produção tradicional, promovem a biodiversidade funcional no campo e contribuem com uma maior resiliência dos ecossistemas (PAULI et al., 2018).

As intervenções alimentares nas escolas, por meio da participação dos pequenos agricultores em mercados institucionais: a) na educação, com o aumento da escolarização e redução no abandono escolar; b) na saúde, pelo melhoramento nutricional e cognitivo das crianças em idade escolar; c) na agricultura, pelo apoio aos rendimentos dos agregados familiares beneficiários e das famílias de agricultores; d) no desenvolvimento de pequenas empresas que estão vinculadas com todo o processo, desde a produção até o consumo final, como por exemplo, empregando cozinheiros e outros envolvidos na prestação de serviços alimentares (GELLI et al., 2016). Uma reação em cadeia que implique melhor alimentação, beneficios à saúde e aumento de rendimento escolar, depende da apropriada implementação do programa, da habilidade das comunidades em participar ativamente nos programas e do esforço das instituições públicas envolvidas (PAULI et al., 2018).

\section{Empreendimentos rurais do Rio Grande do Sul e da COOESPERANÇA}

\section{Crédito e Financiamento dos EES: diagnóstico preeliminar}

De acordo com os dados do mapeamento da Secretaria Nacional de Economia Solidária (SENAES)2 , realizado entre 2012 e 2013, o estado do Rio Grande do Sul (RS) possuía 1.696 Empreendimentos de Economia Solidária (EES). Destes, quase $50 \%$ (845) são empreendimentos de agricultura familiar. Outro dado que merece destaque é que $38 \%$ dos empreendimentos gaúchos são rurais, $46 \%$ são urbanos e $16 \%$ são um híbrido de empreendimentos urbanos e rurais (ver figura 01, abaixo). Verifica-se, portanto, no estado gaúcho, um equilibrio entre empreendimentos urbanos e rurais e da importância da agricultura urbana, uma vez que se observa a existência de um maior percentual de empreendimentos da agricultura familiar em relação ao percentual total de empreendimentos rurais.

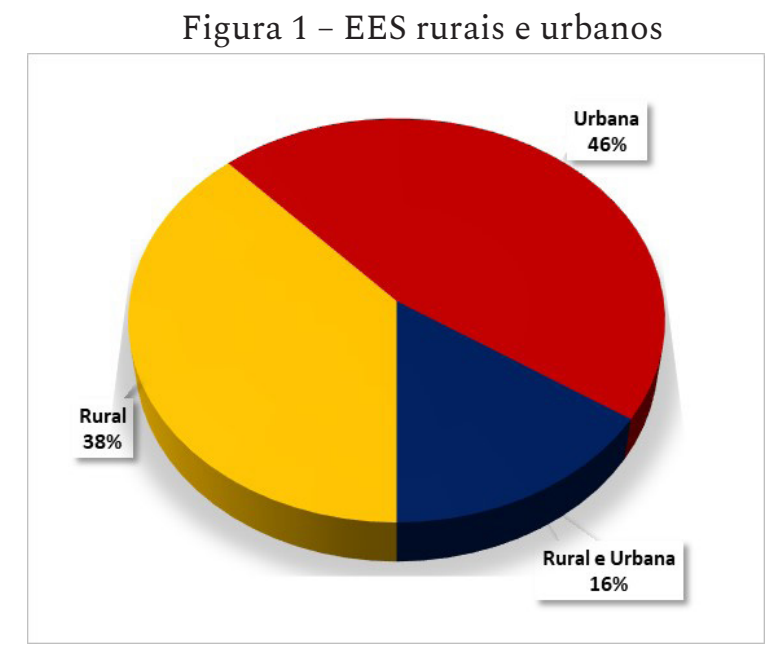

Fonte: Adaptado de SENAES (2013).

As Figuras $2 \mathrm{a}$ e $2 \mathrm{~b}$ apresentam, respectivamente, informações relativas às necessidades de financiamento e o acesso efetivo a crédito no ano anterior à realização da pesquisa. Os resultados mostram que $54 \%$ dos EES entrevistados declararam ter necessidade de financiamento. Apesar disso 84\% dos EES gaúchos declararam não haver buscado crédito ou financiamento. Outros $11 \%$ buscaram e obteviveram crédito ou financiamento, enquanto que $5 \%$

2 Disponível em: http://sies.ecosol.org.br/atlas. Acesso em 30/08/2019. 
buscaram, mas não obteveram crédito ou financiamento. Essas informações, apesar de considerarem a totalidade dos empreendimentos (rurais e urbanos) evidenciam a necessidade de aportes financeiros para garantir a viabilidade dos EES e das dificuldades na obtencão de crédito.

Figura 2 - Necessidades de financiamento e o acesso efetivo a crédito - RS

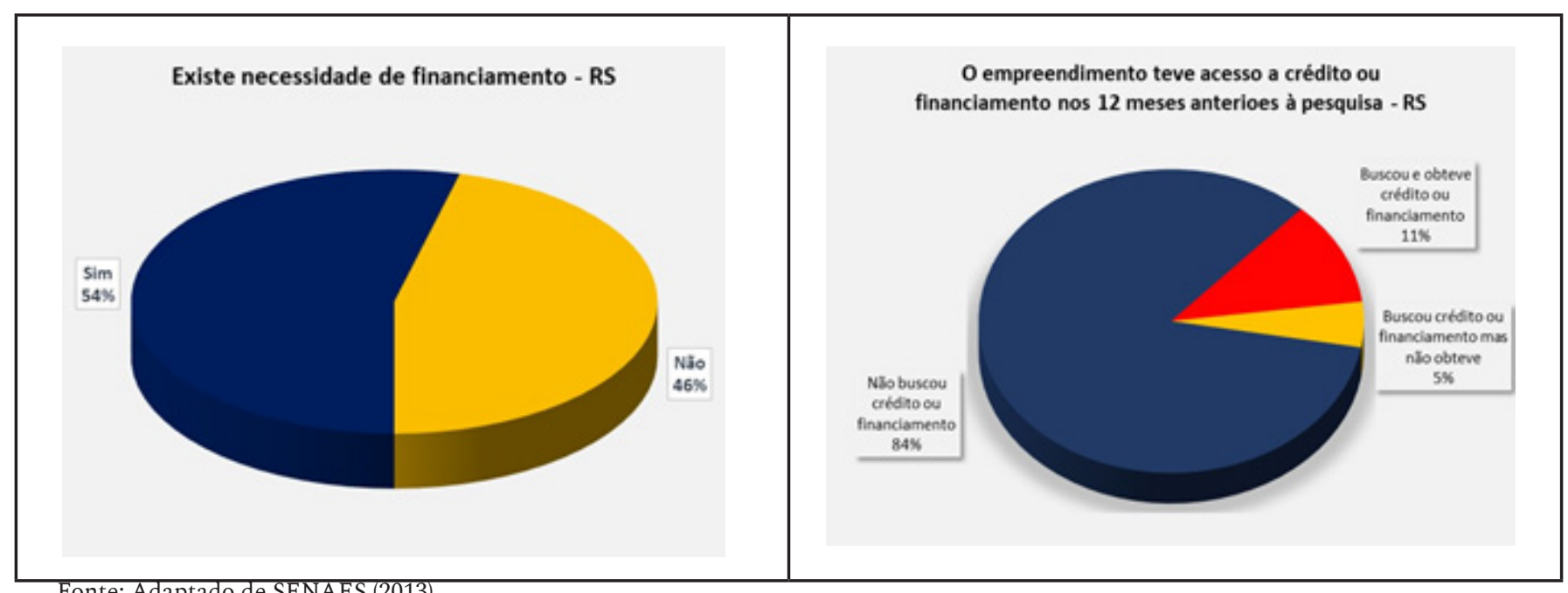

Fonte: Adaptado de SENAES (2013).

Um dos fatores que afastam os atores sociais partícipes da ES da busca de finaciamento nas instituições de crédito convencionais é decorrente das inúmeras dificuldades que enfrentam para sua obtenção, devido à burocracia e às exigências do sistema financeiro convencional, que acabam por excluir um público, considerado de alto risco e/ou com poucas garantias reais de promover o pagamento dos empréstimos no futuro (NEVES, 2016). Na verdade, os dados das Figuras 2a e 2b evidenciam duas faces perversas que reduzem o acesso ao crédito de um segmento social que luta por garantias de sobrevivência: a primeira é a negativa em buscar crédito por parte dos trabalhadores, que nem chegam a procurar pelo sistema financeiro convencional em virtude dos constrangimentos que enfrentam; a segunda é a necessidade de um tipo de crédito especial para este público.

Assim, os programas de fomento produtivo de investimento e custeio, tal como o PRONAF, vêm ao encontro das necessidades de parte deste público, ou seja, dos agricultores familiares. Contudo, os estudos mais recentes mostram que o PRONAF, nos últimos anos vem atendendo proporcionalmente mais os agricultores familiares mais capitalizados, o que poderá explicar uma menor adesão dos associados da COOESPERANÇA, conforme será discutido na próxima seção. O PRONAF é uma política de crédito que se transformou em importante fonte de financiamento público para a agricultura familiar, porém, se apoia em lógica evolucionista no periodo recente que demonstra a elegibilidade dos agricultores familiares com maiores níveis de renda em termos de beneficiários preferenciais (AQUINO E SCHNEIDER, 2015).

Referindo-se aos EES, ressalta-se que um avanço em prol do desenvolvimento da ES em seu conjunto, poderia ocorrer caso se enfatizasse incentivos financeiros que incluíssem as iniciativas do EES urbanos e os empreendimentos urbano-rurais.

Figura 3 - Destino do resultado da atividade econômica - RS

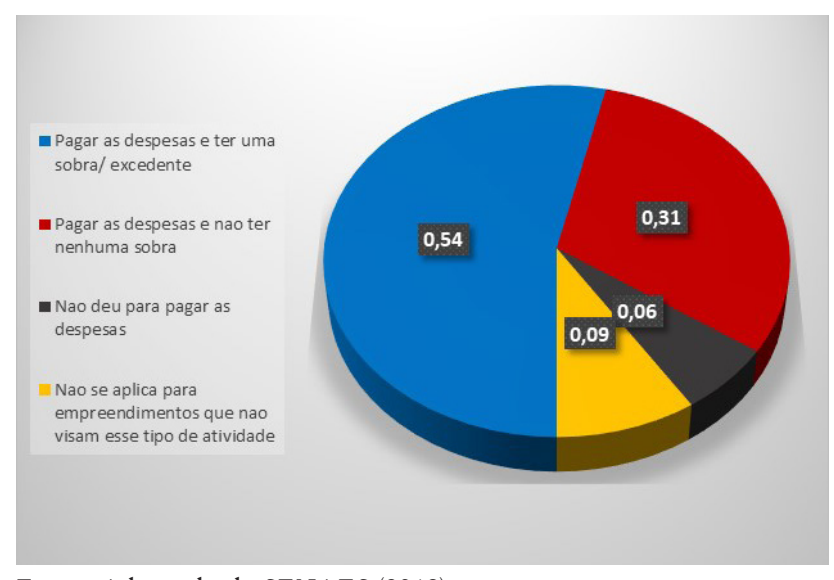

Fonte: Adaptado de SENAES (2013). 
Os dados da Figura 3 mostram ainda que para 54\% dos EES, os resultados da atividade econômica foram suficientes para pagar as despesas e ainda geraram uma sobra (ou excedente). Contudo, em 31\% deles, os empreendimentos puderam apenas quitar as despesas, não havendo nenhuma sobra. Ademais, embora em menor expressividade, não se pode ignorar que em $6 \%$ dos EES, os resultados financeiros não foram suficientes para quitar os custos geradas pelo processo produtivo.

\section{O acesso ao PNAE e ao PRONAF pelos associados da COOESPERANÇA}

Conforme foi discutido nas seções anteriores, é de fundamental importância as políticas públicas para os EES e, especialmente para o desenvolvimento da agriculura familiar. O estímulo de produção saudável de alimentos via agroecologia ou produção orgânica para além de geração de renda de quem produz, é um direito humano de acesso à toda a população. A participação social e o fortalecimento desse tipo de produção no ideário e fomento através de políticas públicas vêm se consolidando no Brasil. Esse movimento, em seus pilares básicos de atuação, criam as condições para disputar uma agenda política, cabendo ao Estado brasileiro apoiar e fortalecer esses modelos de agricultura (MOURA, 2017).

No que se refere ao acesso dos agricultores associados da COOESPERANÇA às políticas públicas voltadas à agricultura, tem-se que 59\% deles acessam o PRONAF e 34\%, ao PNAE. A quantidade de agricultores que mencionaram não acessarem as duas políticas é de 34\% - outros agricultores não souberam informar ou não responderam (ver Figura 4).

Figura 4 - Acesso ao PRONAF pelos agricultores do Projeto Esperança/Cooesperança

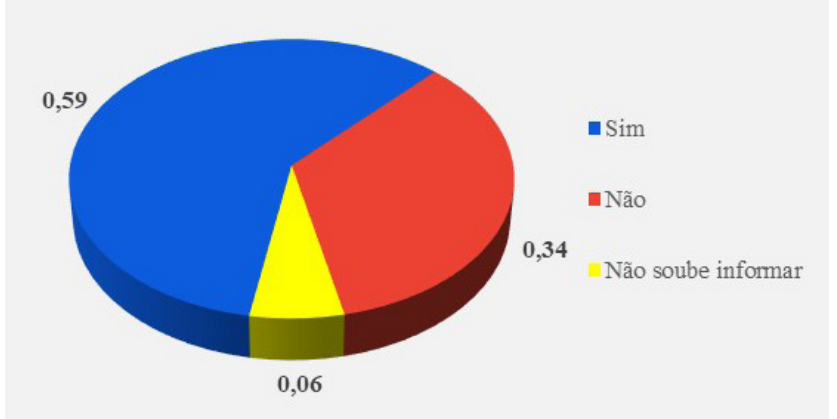

Fonte: elaboração própria, com dados primários.

Vale a pena observar algumas das justificativas dos agricultores para o não acesso às políticas. No caso do PRONAF, um agricultor mencionou não ter tido oportunidade para acessar o programa; outro mencionou que não estava registrado, o que impediu seu acesso; outro ainda, destacou a dificuldade de acesso e a burocracia no acesso como impeditivo para o acesso ao programa. Outra justificativa foi que o acesso deveria ter sido feito em grupo, porém o grupo se endividou, dificultando o acesso. Por fim, um agricultor mencionou que por se assentado novo, teria direito à fomento e que, por isso, se acessasse o PRONAF, perderia o fomento. Destacou ainda que muitas pessoas possuem dívidas ativas com o programa, em virtude das safras ruins (que impossibilitaram os pagamentos). Assim, atualmente existe a necessidade de avalista para a concessão do crédito, sendo difícil encontrar quem queira ser avalista.

Figura 5 - Acesso ao PRONAF pelos agricultores do Projeto Esperança/Cooesperança

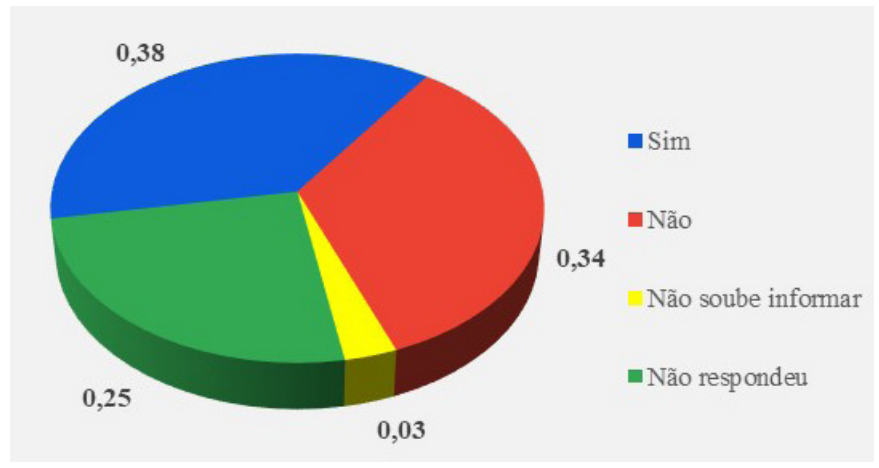

Fonte: elaboração própria, com dados primários.

Com relação ao PNAE observou-se que nem todos os agricultores familiares associados à COOESPERANÇA tinham conhecimento da existência desse programa, e nem mesmo de seus objetivos. Um dos associados atribuiu a dificuldade de acesso ao programa aos processos burocráticos envolvidos e; outro ainda, mencionou não ter registro; 
e um último declarou que não acessava ao PNAE devido às especificidades produtivas do empreendimento, que não atendia às necessidades requeridas pelas escolas públicas do município de Santa Maria.

A COOESPERANÇA compreende um formato articulador de empreendimentos de economia popular e solidária, cuja base assenta-se em um eixo comum baseado nos princípios da solidariedade, sendo uma das mais conhecidas experiencias consolidadas de ES no Brasil. A importância da COOESPERANÇA não reside apenas em função do grande número de associados que a compõe, mas devido ao crescente número de atores sociais mobilizados através dos movimentos como a Feira Nacional de Economia Solidária, realizada anualmente no município de Santa Maria (RS) há mais de duas décadas. Organizada por um grupo de organizações, entre elas a Caritas Brasileira e o Fórum Brasileiro de Economia Solidária (FBES), a Feira de Santa Maria, como é conhecida, conta com a participação de EES e grupos de apoio à ES de todas as regiões do Brasil e também de outros países (IPEA, 2016).

A COOPESPERANCA vem assegurando sua posição de referência nacional e internacional para economia solidária, cooperativismo e inclusão social, aliada aos princípios de sustentabilidade ambiental. Desde o projeto original realizado em 1988, que previa a construção de um Terminal de Comercialização, houve uma duplicação de espaços fixos de comercialização e a criação de outros pontos de comercialização nas feiras para produtos de EES rurais e urbanos, que agora somam mais de 260 unidades e envolve aproximadamente 5.200 famílias em produção (DILL, s/d) ${ }^{3}$. Outra alteração importante foi a possibilidade de comercialização nos mercados institucionais. Esse processo é um dos fatores que vem permitindo a ampliação e reprodução das familias associadas a essa cooperativa.

Além das famílias urbanas e rurais, alguns novos segmentos foram incorporados à COOESPERANÇA, como povos indígenas, quilombolas e catadores de lixo. Toda essa oferta de produtos artesanais locais e a geração de conhecimento de tecnologias sociais vem trazendo benefícios aos consumidores locais e regionais. O público alvo de consumidores acaba se constituindo em um nicho de consumo consciente. Estes são beneficiados pelo acesso a alimentos saudáveis e com preços muitas vezes inferiores aos praticados nos supermercados, especialmente devido a dois fatores: i) a venda direta ou sem intermediação e, ii) a prática do preço justo que atua como princípio ético da cooperativa. Pode-se vislumar, não raras vezes, o reaparecimento de antigas práticas de trocas diretas entre os associados à Cooperativa, possibilitado pela diversificação/especialização produtiva interna, associado à ideologia associativa que favorece o bem-estar em detrimento da ideia de maximização de lucro.

\section{Considerações finais}

A análise apresentada neste capítulo denotou que, embora tivessemos afastados estruturalmente por longo tempo, de políticas específicas para a agricultura familiar, após 1995 e especialmente nas duas últimas décadas, obteve-se avanços sem prescendentes. As políticas públicas foram construídas a partir do reconhecimento de esforços da participação social e foi observado tanto na obtenção de recursos para fomento de investimento como custeiao das atividades, mormente rurais e da ampliação de mercados via compras institucionais. Porém, sem entrar nas contradições que envolve os debatem em torno do tema, observou-se o desmantelamento de algumas dessas políticas específicas de mercado, no caso do PAA.

No que diz respeito às políticas de fomento específico aos agricultores familiares a exemplo do caso do PRONAF, observou-se a existência de concentração de recursos no segmento mais capitalizado desse grupo social. Devido a essa realidade, parte dos agricultores familiares que normalmente se associam às cooperativas da ES como a COOESPERANÇA, acabam tendo acesso mais restrito, ou até mesmo sendo alijados em termos de acesso a essa política pública. Ademais, depreende-se que apesar da manutenção de políticas para os agricultores familiares, ainda persistem outros problemas como dificuldades de operacionalização, e fragilidades na assistência técnica de extensão rural. Este entrave poderá ser contornado a partir de uma ampliação de espaços discussão, e trocas de informações entre os associados da COOESPERANÇA, a partir da experiência de acessibilidade de uma parcela dos agricultores familiares que já foram bem-sucedidos no acesso à essa política.

Além disso, sugere-se maior aproximação das universidades em processos de extensão, via incubadoreas tecnológicas que, poderão, além de contribuir e avançar na aproximação do público alvo às políticas existentes, assumir uma posição ativa na construção de novas agendas. De um lado, pensar formas de ampliação dos objetivos dessas políticas e o retorno daquelas que vêm recuando, ou se subordinando em um escopo ampliado das políticas atuais, parece haver aí uma necessidade de discussão de avanços no que deve conter uma política pública de ES.

De forma geral, presume-se que para os associados da ES e da COOESPERANÇA, o acesso as políticas PRONAF e PNAE contribuem para o fortalecimento dos empreendimentos que envolvem a agricultura familiar. Porém, ao se considerar o conjunto dos atores sociais envolvidos, vislumbram-se demandas específicas que compreendem incentivos de inclusão de pessoas por meio da ES. Para tal, o trabalho associado ou cooperado precisa promover outro tipo de desenvolvimento emancipatório com fomento à miriade de iniciativas de produção, aos aspectos da comercialização e o apoio financeiro.

3 Entrevista direta com a Irmã Lourdes Dill (principal liderança da COOESPERANÇA). 
O cerne de uma política de economia solidária necessita que todos seus participantes, urbanos e rurais, pertencentes a EES formais e informais, sejam potencializados a partir do reconhecimento de suas demandas socioeconômicas. Neste sentido, não basta propulsionar as tecnologias sociais a partir do reconhecimento de sua existência, porém ampliar processos de educação e formação para assegurar a consolidação dos EES. Tantos os empreendimentos rurais e urbanos precisam de incentivos para iniciar os processos produtivos e construção de mercados. Pode-se concluir que os agricultores familiares que acessam ao PNAE, não apenas ampliam os canais de distribuição de seus produtos, mas fornecem alimentos saudáveis às escolas públicas municipais. Para o caso da ES, poderia se pensar numa política a exemplo do PNAE que favorecesse o segmento urbano dos empreedimentos. O conteúdo dessa política vai além dos propositos deste trabalho. Enfim, o desenvolvimento da ES deve contar com aspectos da transversalidade e intersetorialidade de políticas, capazes de incentivar a formação de redes intra e intercooperativas.

Neste trabalho, procurou-se mostrar que, apesar da continuidade de algumas políticas importantes que também são acessadas pelos agricultores familiares da ES e COOESPERANÇA, ainda persistem problemas que conforme visto, necessitam de constante apoio em diferentes níveis de atuação, se o ideario for promover o desenvolvimento dos empreendimentos e do contexto sócio territorial da ES e COOESPERANÇA. Mas ficou evidente que o declínio das políticas públicas mais abrangentes, direcionadas aos EES que tiveram importancia crucial a partir de segunda metade da década de 2000, com a criação da SENAES, vem reduzindo o almejado fortalecimento dos empreendimentos urbanos, rurais e mistos.

\section{Referências bibliográficas}

ABRAMOVAY, R. e VEIGA, J. E. Novas Instituições para o Desenvolvimento Rural: o caso do Programa Nacional de Fortalecimento da Agricultura Familiar (PRONAF). Texto para discussão n. 641. Brasília-DF, Convênio FIPE/ IPEA 07/97. Abril de 1999, 51p.

AQUINO, J. R.; GAZOLLA, M.; SCHNEIDER, S. O financiamento público da produção agroecológica e orgânica no Brasil: inovação institucional, obstáculos e desafios. Disponível em: http://www.corecon-rn.org.br/wp-content/ uploads $/ 2017 / 09 / \mathrm{O}-$ Financiamento-P\%C3\%BAblico-da-Produ\%C3\%A7\%C3\%A3o-Agroecol\%C3\%B3gica-eOrg\%C3\%A2nica-no-Brasil-Inova\%C3\%A7\%C3\%A3o-Institucional-Obst\%C3\%A1culos-e-Desafios.pdf.

BECKER, C; SACCO DOS ANJOS, F.; DAL MOLIN, L. H. Uma aproximação entre mercados institucionais e a abordagem das capacitações em duas regiões gaúchas. In: 7º ENCONTRO DE ECONOMIA GAÚCHA, 2014, Anais ... Porto Alegre, 2014. Disponível em: <http://www.fee.rs.gov.br/wp-content/uploads/2014/05/201405267eegmesa27-aproximacaomercadosinstitucionaisabordagemcapacitacoes.pdf >. Acesso em: 04 out. 2016).

BRASIL. Pronaf - Programa Nacional de Fortalecimento da Agricultura Familiar. BNDES. 2019.

DEUBEL, André-Noël Roth. Políticas Públicas: Formulación, Implementación e Evaluación. Bogotá: Ediciones Aurora, 2006.

DI GIOVANNI, Geraldo. As estruturas Elementares das Políticas Públicas. Caderno de Pesquisa, n. 82, NEPP/ UNICAMP, 2009.

FORNAZIER, A. \& BELIK, W. (2013) Produção e consumo local de alimentos; novas abordagens e perspectivas para as politicas públicas. Segurança alimentar e nutricional. Campinas.

GRISA, C. \& PORTO, S. I. (2015). As contribuições e desafios para o desenvolvimento rural.in Politicas Públicas e desenvolvimento rural no Brasil. Porto Alegre. Editora da UFRGS.

GRISA, C.; Schneider, S. Três gerações de políticas públicas para a agricultura familiar e formas de interação entre sociedade e Estado no Brasil. In: GRISA, C.; SCHNEIDER, S. (Orgs.). Políticas públicas de desenvolvimento rural no Brasil. Porto Alegre: Editora da UFRGS, 2015.

GELLI. A. et al. Evaluation of alternative school feeding models on nutrition, education, agriculture and other social outcomes in Ghana: rationale, randomised design and baseline data.Journals Trials, v. $17,2015$.

GOODMAN, D. Rural Europe redux? Reflectionson alternative agro-food networks and paradigm change. Sociologia Ruralis, 44 (1) , p.3-16, 2004. 
MALUF, R. S. Mercados agroalimentares e a agricultura familiar no Brasil: agregação de valor, cadeias integradas e circuitos regionais. Ensaios FEE, P. Alegre, v. 25, n.1, p. 299-322, 2004.

MOURA. i. f. Antecedentes e Aspectos Fundantes da Agroecologia e Produção Orgânica na Agenda das Políticas Públicas no Brasil. In: A Política Nacional de Agroecologia e produção Orgância no Brasil: Uma Trajetória de Luta Pelo desenvolvimento Rural Sustentável. Organizadores: Regina Helena Rosa.Sambuichi et. al.) Brasília, IPEA, 2017.

MULLER, Pierre. Les politiques publiques. Collection Quesais-je? n. 2354, 4⿳⺈ ed. Francesa, PUF, Junio de 2000. JOLLY, Jean-François \& VARGAS, Carlos Salazar (Tradución). Las Políticas Públicas. Bogotá-Colombia: Universidad Externado de Colombia, 2002.

NEVES, Ednalva Felix. Percepções sobre as contradições e dificuldades de inserção e sobrevivência dos empreendimentos de economia solidária no mercado. Tese (Doutorado em Desenvolvimento Econômico). Instituto de Economia/UNICAMP, Campinas, 2016.

Agência de Desenvolvimento de Santa Maria (Adesm). Movimento A Santa Maria que queremos. Plano Estratégico de Desenvolvimento de Santa Maria. Programa de Pós-Graduação em Administração da UFSM. 2013. Disponível em: http://coral.ufsm.br/midia/?p=9364. Acesso em 12/12/2019.

Pauli, Rita Inês Paetzhold; SCHULZ, Jéferson Réus da S.; Zajonz, Bruna Tadielo; STEINDORFF, Kelen. Análise comparativa do desenvolvimento do PNAE entre as escolas estaduais e municipais de Santa Maria (RS) à luz dos elementos potenciais da Segurança Alimentar e Nutricional (SAN). Revista Estudos Sociedades e Agricultura, Rio de Janeiro, v. 26, n. 2, p. 447-479, jun./set. 2018.

SCHIOCHET, V. Políticas Públicas. In: HESPANHA, P., et. all. Dicionário Internacional da Outra Economia. São Paulo: Ed. Almedina. 2009.

MALUF, R. S. Mercados agroalimentares e a agricultura familiar no Brasil: agregação de valor, cadeias integradas e circuitos regionais. Ensaios FEE, P. Alegre, v. 25, n.1, p. 299-322, 2004.

SILVA, S. P. Políticas públicas, agricultura familiar e desenvolvimento territorial. Cadernos Gestão Pública e Cidadania, v. 16, p. 1-19, 2011.

SONNINO, R.; MARSDEN, T. Beyond the divide: rethinking relationshipsbetween alternative and conventional foot networksin Europe. Journal of Economic Geography, 6. 2006.

SOUZA, Celina. Políticas Públicas: uma revisão da literatura. Revista Sociologias. Porto Alegre, ano 8, nº 16, jul/ dez 2006, p. 20-45.

SOUZA-ESQUERDO, V. F. de; BERGAMASCO, S. M. P. P. Análise Sobre o Acesso aos Programas de Políticas Públicas da Agricultura Familiar nos Municípios do Circuito das Frutas (SP). Revista de Economia e Sociologia Rural, v. 52, Supl. 1, p. S205-S222, 2014. Disponível em: https://periodicos.ufsm.br/extensaorural/article/ view/14539.

INSTITUTO DE PESQUISA APLICADA (IPEA). Os novos dados do mapeamento de economia solidária no Brasil: nota metodológica e análise das dimensões socioestruturais dos empreendimentos. Relatório de Pesquisa. Brasília. IPEA, 2016. 